\title{
Folic acid usage and awareness in pregnant women in I stanbul, Turkey
}

\author{
Nilgün Tekkesin ${ }^{1}$, Figen Taser ${ }^{2}$ \\ 1. Memorial Hospital, Biochemistry Laboratory, Istanbul, Turkey. 2. Memorial Hospital, Obstetrics and Gynocology \\ Department, Istanbul, Turkey
}

Correspondence: Nilgün Tekkesin. Address: Memorial Hospital, Biochemistry Laboratory, Istanbul, Turkey. Telephone: 090-212-314-6666. E-mail: niltek@hotmail.com

Received: J une 27, 2012

Accepted: August 5, 2012

Published: September 1, 2012

DOI : $10.5430 /$ jha.v1n1p9

URL: http://dx.doi.org/10.5430/jha.v1n1p9

\begin{abstract}
Intake of folic in the periconceptional period reduces the risk of neural tube defects (NTDs). The aim of this study was to assess the level of awareness regarding the use of folic acid in pregnacy. We assessed the consumption of folic acid during pregnancy among Turkish women presented to the hospital and analyzed the difference of folic acid supplementation between planned and unplanned pregnancies. Of the 1076 women, $677(62.9 \%)$ reported current use of a prenatal folic acid at the time of the department visit, while 399 pregnant women (37.0\%) identified themselves as non-users ( $p=0.006)$. In the unplanned pregnancy group, 302 (65.22\%) women reported taking folic acid during pregnancy, but 161 (34.77\%) women began three months prior to conception as recommended by their gynecologists $(p<0.0001)$.

Although, the study group was a significant user with a high awareness of folic acid, our findings may not be generalizable to other areas of the country. Because, parcitipants were likely to be one of the most educated group with a medium or high socio-economical status. Besides these hopeful results, we believe the necessity to re-evaluate our educational strategies and consider reduction of unplanned pregnancies as part of our goals.
\end{abstract}

\section{Key words}

Folic acid, Neural tube defects, Pregnancy

\section{Introduction}

Each year, 300,000 to 400,000 infants worldwide are born with neural tube defects (NTDs) including spina bifida and anencephaly ${ }^{[1]}$. This accounts for an estimated 41000 deaths and 2.3 million disability-adjusted life years ${ }^{[2]}$.

In an effort to curtail these preventable birth defects, the Food and Drug Administration (FDA) and the US Center for Disease Control and Prevention (CDC) have suggested that women of childbearing age consume a minimum of $400 \mu \mathrm{g}$ $[0.4 \mathrm{mg}]$ of folic acid daily ${ }^{[3,4]}$. Since then, many other countries have made similar recommendations ${ }^{[5-7]}$. A randomized controlled trial in Hungary showed a reduction in recurrent NTDs with folic acid supplementation ${ }^{[8]}$. This led to many high-income countries adopting policies recommending supplementation for women planning for pregnancy ${ }^{[9]}$. Morris and Wald ${ }^{[10]}$ showed an overall $93 \%$ decrease in prevalence of NTDs at birth ${ }^{[10]}$. This was consequent upon the 
combination of second-trimester screening and termination of affected pregnancies (34\%) and an underlying decrease in the prevalence of affected conceptions (59\%), which could in part be explained by folic acid supplementation.

A well-organized periconceptional folic acid supplementation programme requires a high proportion of pregnancies to be planned for by health providers and the general public, with a successful functioning health system, social marketing, social mobilization, and advocacy efforts ${ }^{[1]}$. Unplanned pregnancies may account for one-third to one-half of all pregnancies even in high-income settings ${ }^{[12]}$. This suggests that supplementation policies have had limited impact on the population, even in high-income countries ${ }^{[13]}$. The population living in poor folate-diet consuming countries exhibited the highest incidence of NTDs ${ }^{[14,15]}$. Low maternal educational status in high-income countries is associated with higher risk of NTDs ${ }^{[16]}$.

Turkey is one of the low-income countries and has a high reported prevalence rate of NTDs at birth ${ }^{[17]}$. A national survey conducted in 1993-1994 showed a perinatal (28 gestational weeks through 7 days of life) prevalence of 4.3 and 4.9 NTDs/1000 births in northern and eastern Anatolia respectively, compared with 3/1000 for the whole country ${ }^{[17]}$. Although, the international data on folic acid usage and awareness are well studied, there were a few published reports that investigated the use of folic acid in pregnant women in Turkey. This information is important since the ultimate goal of any folic acid awareness campaign is to increase consumption of folic acid, and so improve the blood folate status of women of childbearing age. To increase the awareness of the benefit of folic acid supplement in preventing NTDs and periconceptional use of folic acid, we assessed the consumption of folic acid during pregnancy among Turkish women that visited to the hospital and analyzed the difference in folic acid use between planned and unplanned pregnancies. We wanted to report on awareness and use was equally reported.

\section{Materials and methods}

The study population included 1076 pregnant Turkish women from the city of Istanbul. The Memorial Hospital provides health care services to a population of medium to high socioeconomic status. All eligible women underwent antenatal screening tests as they attended the Obstetrics and Gynecology Clinic (OGC). The doctors would then verify from the clients whether it was a planned or an unplanned pregnancy and noted accordingly in the screening questionnaire completely designed for his purpose. This comprises an anonymous questionnaire that included questions on demographic background, knowledge and use of folic acid and then administered to the pregnant women. All the pregnant women were sufficiently educated enough to fill out the questionnaire. Therefore none of them were rejected. In evaluating rates of folic acid use, comparisons were made between patients reporting unplanned and planned pregnancies respectively.

This study received the approval of the Memorial Hospital Review Board.

\subsection{Statistical methods}

The study data were organized with the Excel software program and processed using the Statistical Package for the Social Sciences (SPSS), Version 11.5. Statistical associations between pairs of categorical variables with two or three groups were assessed using Chi-Square analysis $\left(\mathrm{x}^{2}\right)$ and statistical significance was set at $P<.05$.

\subsection{Ethics statement}

The study protocol was approved by the institutional review board of Sisli Memorial Hospital (IRB No. 23-15-2012). Informed consent was confirmed (or waived) by the IRB.

\subsection{Results}

We screened the data input on folic acid use from 1 January 2011, through 12 January 2012. One thousand and seventy-six pregnant women participated in the study during the 121/2 month period. The mean maternal age among 1076 Turkish 
women was $27.6 \pm 4.9$ years (range 20-42). The average number of pregnancies per patient was 2.2 (range 1-7) with an average of 1.2 previous live births per patient (range $0-4$ ). The average estimated gestational age was 112.2 days (range 13-140 days) (see Table 1).

Table 1. Patient characteristics

\begin{tabular}{ll}
\hline Characteristic & Number/Percentage (Range) \\
\hline Total patients & 1076 \\
Average age & $27.6 \pm 4.9$ years (range 20-42) \\
Number of pregnancies & $2.2(1-7)$ \\
Previous live births & $1.2(0-4)$ \\
Average gestational age & 112.2 days $(13-140)$ \\
Current prenatal folic acid use & $62.9 \%$ \\
\hline
\end{tabular}

Of all the pregnant women investigated, $62.9 \%(n=677)$ reported current use of a prenatal folic acid at the time of the hospital visit, while $399(37.0 \%)$ identified themselves as non-users because of unawareness $(p=0.006)$. The non-users were first-time pregnant women. The users were divided into unplanned $(\mathrm{n}=463,68.3 \%)$ and planned $(\mathrm{n}=214,31.6 \%)$ pregnancy groups. We noted a significant difference in prenatal folic acid use between patients who had an unplanned pregnancy and those who had a planned pregnancy (Table 2).

Table 2. Comparison of consumption of folic acid, between planned and unplanned pregnancies

\begin{tabular}{llll}
\hline Variable & Unplanned pregnancy $(\mathbf{n}=\mathbf{4 6 3})$ & Planned Pregnancy $(\mathbf{n}=\mathbf{2 1 4})$ & $\boldsymbol{P}$ \\
\hline Prior to Pregnancy & $161(34.7 \%)$ & $214(100 \%)$ & $<0.0001$ \\
During Pregnancy & $302(65.3 \%)$ & & \\
\hline
\end{tabular}

In the unplanned pregnancy group, 302 (65.3\%) women reported taking folic acid during pregnancy, but $161(34.7 \%)$ of them started using folic acid three months prior to conception as recommended by gynecologists $(p<0.0001)$. In planned pregnancy, all (100\%) women reported using folic acid preconceptionally. Among them $66.6 \%$ said that they had received these recommendations and knew that folic acid could prevent NTDs. The others (33.4\%) reportedly knew that taking folic acid could "help" the fetus, but could not define specific health benefits.

\subsection{Discussion}

The prevalence of NTDs is three times higher in Turkey (3/1000) than in Western countries $(1 / 1000)^{[17-19]}$. Geographical distribution of NTDs in the country confirms a relationship between the socioeconomic status and environmental factors for the development of NTDs ${ }^{[17]}$. In a multi-ethnic study, the lower use of folic acid supplements in Arab/Turkish ethnicities, is related to socio-economic factors rather than to lower educational attainment ${ }^{[20]}$.

As far as Turkey is concerned, the available data on the possible use of folic acid among pregnant women are limited and to the best of our knowledge, no data exist for Istanbul. Istanbul, which has experienced rapid urbanization and industrialization in the past few decades, is an overpopulated city, located in the European part of the Turkish territory. The citizens are thought to be one of the most educated groups, with medium or high socio-economical status in Turkey. In the present study we found that a large number of women take folic acid during pregnancy. A survey of women in the first trimester of pregnancy showed that $62.9 \%$ of them were users of folic acid and $100 \%$ of planned and $34.7 \%$ of unplanned pregnant women reported taking folic acid periconceptionally. The clear recommendations seemed effective enough that a significant percentage of pregnant clients attending the OGC reported being on current folic acid supplement. The high educational status of the population could be responsible for the large number of women using folic acid supplement. 
The awareness and use of folic acid among pregnant women in the study area were as high as those in other parts of the world. Data reported during the past 7 years from United Arab Emirates ${ }^{[21]}$, Norway ${ }^{[22]}$, Israel ${ }^{[23]}$, Qatar ${ }^{[24]}$, and the United States ${ }^{[25]}$ indicate awareness ranging from $46.4 \%$ (UAE) to $85.2 \%$ (Israel). The reported use of folic acid among reproductive-age women in these and other countries was also higher, ranging from $20.3 \%$ in Qatar, to $68 \%$ in Spain ${ }^{[21-26]}$. Turkey reported a lower rate of awareness (22\%) among women who were delivered of live-born infants during the preceding 12 months ${ }^{[27]}$. This study could serve as a good indicator for the improvements in Turkish health organizations.

Our findings were consistent with others who have reported that folic acid awareness predicts folic acid use ${ }^{[22,23,26,28]}$. In our study, women who were aware of the importance of folic acid were 1.6 times more likely to take periconceptional folic acid than were women who were unaware of it. Despite the fact that almost $33.4 \%$ of the women had no clear picture of the benefits of folic acid usage, they began taking folic acid before conception.

At the time the present survey was completed, premarital health examination at the local maternal and child health care centers was mandatory in Turkey for both men and women. This provides an opportuned setting for educating young couples about folic acid use, and its role in preventing NTDs. In Turkey, women who are planning marriage or pregnancy are advised to take $400 \mu \mathrm{g}$ of supplemental folic acid every day starting before conception, through the end of the first trimester of pregnancy. In unplanned pregnancy, folic acid supplement is always recommended during pregnancy. There was a correlation between the doctors' recommendations and the actual degree to which women took folic acid prior to conception (data not given). Given these findings, this study suggests a potential role for the OGC in the prevention of NTDs, but it does not suggest that such an intervention would be effective in improving the rates of folic acid supplement among pregnant women. Special intervention plans should be developed for the population based on its cultural and socio-economic characteristics. This intervention could be as simple as screening childbearing-age women for folic acid use and providing information on the benefits of folic acid supplementation, as well as a list of community resources available to these patients. A detailed intervention plan should include three basic strategies: diet, folic acid supplement, and food fortification ${ }^{[29]}$. Other studies have reported that popular newspapers and the electronic media are more effective than printed material disseminated by health authorities ${ }^{[30]}$.

The main limitation of our study was that it was conducted in only one province. Therefore, our findings may not be generalizable to other areas of the country. In addition, the study subjects were not randomly selected: those women who came to seek early prenatal care may be more conscious about their health and that of their unborn babies, or may enjoy a higher socioeconomic status than those who did not, which would result in an overestimation of folic acid awareness, use, and blood folate levels in the population. Third, we did not collect individual or family income data, which could confine the association between parity or other factors and use of folic acid. However, since the subjects were living in a socially and economically homogeneous geographical area, we do not expect that there was significant limitation.

\section{Conclusion}

Approximately, 1 out of 2 females had used folic acid during their pregnancy. This study suggests the potential extra-need for an educational intervention program as a means to improve folic acid supplement in unplanned pregnancies. Although such an intervention is effective, it targets only women planning a pregnancy or recently pregnant. It is important to train health workers in the community to recommend folic acid before, and not only after, conception. It is important for physicians to encourage a preconception examination in which counseling and recommendations for folic acid supplementation are provided.

\section{References}

[1] Godfrey, P., Oakley, Jr. Centers for Disease Control and Prevention, Atlanta, GA, USA Bulletn of the World Health Organization. 1998; 76 (SuppI 2): 116-117. 
[2] The Global Burden of Disease [Internet]. [[13 September 2009, date last accessed]]. update.2004. http://www.who.int/healthinfo/global_burden_disease/GBD_report_2004update_full.pdf.

[3] Yang, Q.H., Carter, H.K., Mulinare, J., Berry, R.J., Friedman, J.M., Erickson, J.D. Race-ethnicity differences in folic acid intake in women of childbearing age in the United States after folic acid fortification: findings from the National Health and Nutrition Examination Survey, 2001-2002. Am J Clin Nutr. 2007; 85(5): 1409-1416. PMid:17490980

[4] Hamner, H.C., Mulinare, J., Cogswell, M.E., Flores, A.L., Boyle, C.A., Prue, C.E., Wang, C.Y., Carriquiry, A.L., Devine, O. Predicted contribution of folic acid fortification of corn masa flour to the usual folic acid intake for the US population: National Health and Nutrition Examination Survey 2001-2004. Am J Clin Nutr. 2009; 89(1): 305-315. PMid:19056605 http://dx.doi.org/10.3945/ajen.2008.26331

[5] Rasmussen, L.B., Andersen, N.L., Andersson, G., et al. Folate and neural tube defects. Recommendations from a Danish working group. Dan Med Bull. 1998; 45: 213-217. PMid:9587705

[6] Botto, L.D., Lisi, A., Robert-Gnansia, E., et al. (2005). International retrospective cohort study of neural tube defects in relation to folic acid recommendations: are the recommendations working? BMJ bmj.38336.664352.664382.

[7] Kondo, A., Kamihir, O., Shimosuka, Y., Okai, I., Gotoh, M., Ozawa, H. Awareness of the role of folic acid, dietary folate intake and plasma folate concentration in Japan. J Obstet Gynaecol Res. 2005; 31: 172-177. PMid:15771645 http://dx.doi.org/10.1111/j.1341-8076.2005.00265.x

[8] Czeizel, A.E., Dudas, I., Metneki, J. Pregnancy outcomes in a randomised controlled trial of periconceptional multivitamin supplementation. Final report. Arch Gynecol Obstet. 1994; 255: 131-139. PMid:7979565 http://dx.doi.org/10.1007/BF02390940

[9] Centers for Disease Control. Recommendations for the use of folic acid to reduce the number of cases of spina bifida and other neural tube defects. MMWR. 1992; 41(No. RR-1):1-7.

[10] Morris, J.K., Wald, N.J. Prevalence of neural tube defect pregnancies in England and Wales from 1964 to 2004 . J Med Screen. 2007; 14: 55-59. PMid:17626701 http://dx.doi.org/10.1258/096914107781261945

[11] de Benoist, B. Conclusions of a WHO Technical Consultation on folate and vitamin B12 deficiencies. Food Nutr Bull. 2008; 29(2 Suppl): S238-S44. PMid:18709899

[12] Custer, M., Waller, K., Vernon, S., O'Rourke, K. Unintended pregnancy rates among a US military population. Paediatr Perinat Epidemiol. 2008; 22: 195-200. PMid:18298695 http://dx.doi.org/10.1111/j.1365-3016.2007.00896.x

[13] Botto, L.D., Lisi, A., Robert-Gnansia, E., et al. International retrospective cohort study of neural tube defects in relation to folic acid recommendations: are the recommendations working? Br Med J. 2005; 2: 330-571.

[14] Wasserman, C.R., Shaw, G.M., Selvin, S., Gould, J.B., Syme, S.L. Socioeconomic status, neighborhood social conditions, and neural tube defects. Am J Public Health. 1998; 88: 1674-1680. PMid:9807535 http://dx.doi.org/10.2105/AJPH.88.11.1674

[15] Vrijheid, M., Dolk, H., Stone, D., Abramsky, L., Alberman, E., Scott, J.E. Socioeconomic inequalities in risk of congenital anomaly. Arch Dis Child. 2000; 82: 349-352. PMid:10799420 http://dx.doi.org/10.1136/adc.82.5.349

[16] Grewal, J., Carmichael, S.L., Song, J., Shaw, G.M. Neural tube defects: an analysis of neighbourhood- and individual-level socio-economic characteristics. Paediatr Perinat Epidemiol. 2009; 23: 116-124. PMid:19159398 http://dx.doi.org/10.1111/j.1365-3016.2008.00992.x

[17] Tunçbilek, E., Boduroğlu, K., Alikaşifoğlu, M. Neural tube defects in Turkey: prevalence, distribution and risk factors. Turk J Pediatr. 1999; 41(3): 299-305. PMid:10770089

[18] EUROCAT Working Group. Prevalence of neural tube defects in 20 regions of Europe and the impact of prenatal diagnosis, 1980-1986. J Epidemiol Community Health. 1991; 45: 52-58. http://dx.doi.org/10.1136/jech.45.1.52

[19] Van der pal-de Bruin, K.M., De Walle, H.E.K., De Rover, C.M., Jeeninga, W., Cornel, M.C., de Jong-van den Berg, L.T.W., et al.. Influence of educational level on determinants of folic acid use. Paediatr Perinat Epidemiol. 2003; 17: 256-263.

[20] Mohamed, A., Baraka, S., Steurbaut, L. Leemans, W., et.al. Determinants of folic acid use in a multi-ethnic population of pregnant women: a cross-sectional study J. Perinat. Med. 2011; 39: 685-692. PMid:21801033

[21] Abdulrazzaq, Y.M., Al-Gazali, L.I., Bener A, et al. Folic acid awareness and intake survey in the United Arab Emirates. Reprod Toxicol. 2003; 17: 171-176. http://dx.doi.org/10.1016/S0890-6238(02)00120-X

[22] Daltveit, A.K., Vollset, S.E., Lande, B., Oien, H. Changes in knowledge and attitudes of folate, and use of dietary supplements among women of reproductive age in Norway. Scand J Public Health. 2004; 32: 264-271. PMid:15370766 http://dx.doi.org/10.1080/14034940310019515

[23] Amitai, Y., Fisher, N., Haringman, M., Meiraz, H., Baram, N., Leventhal, A. Increased awareness, knowledge and utilization of preconceptional folic acid in Israel following a national campaign. Prev Med. 2004; 39: 731-737. PMid:15351539 http://dx.doi.org/10.1016/j.ypmed.2004.02.042

[24] Bener, A., Al Maadid, M.G., Al-Bast, D.A., Al-Marri, S. (2005). Maternal knowledge, attitude and practice on folic acid intake among Arabian Qatari women. Reprod Toxicol. 
[25] CDC. Use of dietary supplements containing folic acid among women of childbearing age--United States. MMWR Morb Mortal Wkly Rep. 2005; 54: 955-958. PMid:16195694

[26] Coll. O., Pisa, S., Palacio, M., Quinto, L., Cararach, V. Awareness of the use of folic acid to prevent neural tube defects in a Mediterranean area. Eur J Obstet Gynecol Reprod Biol. 2004; 115: 173-177. http://dx.doi.org/10.1016/j.ejogrb.2003.12.009

[27] Unusan, N. Assessment of Turkish women's knowledge concerning folic acid and prevention of birth defects. Public Health Nutr. 2004; 7: 851-855. http://dx.doi.org/10.1079/PHN2004615

[28] Byrne, J., Carolan, S., Arcement, R., et al. An intervention study to increase knowledge and use of folic acid among relatives in neural tube defectaffected families inWashington, D.C. Birth Defects Res A: Clin Mol Teratol. 2005; 73: 424-429. PMid:15880789 http://dx.doi.org/10.1002/bdra.20134

[29] Kaluski, D.N., Amitai, Y., Haviv, A., Goldsmith, R., Leventhal, A. Dietary folate and the incidence and prevention of neural tube defects: a proposed triple intervention approach in Israel. Nutrition Reviews. 2002; 60(10): 303-307. PMid:12392147 http://dx.doi.org/10.1301/002966402320583424

[30] Gil, Z., Aran, A., Friedman, O., Beni-Adani, L., Constantini, S. Folic acid use by pregnant women in Israel for preventing neural tube defects. Harefuah. 2000; 139(11-12): 416-495. PMid:11341184 